\title{
GESTÃO DE ORGANIZAÇÕES CULTURAIS
}

\author{
Rafael Valente \\ Graduando em Jornalismo na Universidade Presbiteriana Mackenzie \\ E-mail: jornalismo.rafael@gmail.com
}

Maurício C. Serafim

Doutorando em Administração de Empresas na FGV-EAESP

E-mail: serafim.gv@gmail.com

\section{Mario Aquino Alves \\ Professor da FGV-EAESP \\ E-mail: mario.alves@fgv.br}

Pedro F. Bendassolli

Professor da FGV-EAESP

E-mail: pedro.bendassolli@fgv.br

Em uma perspectiva ampla, pode-se definir arte como uma manifestação do espírito humano, materializada mediante habilidades e inclinações que repercutem na música, dança, literatura, pintura, enfim, em qualquer atividade de cunho estético desenvolvida pelo homem. Pode parecer distante dessa visão imaginar que a arte deva render recursos financeiros, ou então que possa ser tratada como um negócio a ser gerido como uma empresa. Apesar de o trabalho artístico fundamentar-se em princípios muitas vezes antagônicos aos do mercado e esteja mais associado à produção de cultura e ao interesse público, ele pode ser igualmente concebido como um serviço capaz de gerar lucro. Como em qualquer outro setor, isso ocorrerá na medida em que o setor possuir estratégias de gestão voltadas para atender suas especificidades e profissionais preparados e com visão.
O modelo norte-americano trabalha basicamente seguindo essa premissa de gestão: há investimento público, como também privado, além da captação de receita obtida mediante o lucro oriundo da venda de bilhetes, subscrições e estratégias de marketing. $\mathrm{Na}$ Europa, as organizações culturais são financiadas pelo governo e estão conectadas aos Ministérios da Cultura, que investem bastante e selecionam profissionais capacitados para gerir esses recursos. Ambos os sistemas são estáveis e se destacam pelo alto grau de profissionalismo, assim como pela eficácia na prestação dos serviços.

No Brasil, não são muitas as organizações que trabalham com um modelo profissional de gestão. Geralmente estão ligadas a órgãos públicos, como as Secretárias de Cultura, e dependem dos recursos do governo ou da iniciativa privada. Os problemas administrativos que enfrentam, assim como outras áreas que englobam os serviços não exclusivos do Estado, como a saúde e a educação, se agravaram com a globalização e a crise do Estado (elevados custos e baixa qualidade dos serviços prestados).

$\mathrm{Na}$ tentativa de resolver esses problemas, foi concebido, em 1995, no âmbito da Reforma do Estado, sob a orientação do ministro Luiz Carlos Bresser-Pereira, o modelo de Organizações Sociais. Esse modelo permite que organizações públicas não estatais firmem um contrato de gestão com o Estado e assumam a administração dos serviços considerados não exclusivos. As primeiras OSs concebidas foram a do Laboratório Nacional de Luz Síncroton (LNLS) e a Fundação Roquete Pinto, ambas em 1997. Entre as principais vantagens do modelo, destacam-se: a identificação de estratégias específicas, uma administração mais flexível e com maior 
transparência, controle de resultados, menos burocracia e mais responsabilidade para seus dirigentes.

No âmbito estadual, em São Paulo, criou-se uma legislação similar, embora focada no atendimento exclusivo das áreas da saúde, a partir de 1999, e da cultura, a partir de 2004. Exemplos são a Pinacoteca do Estado de São Paulo e a Orquestra Sinfônica do Estado de São Paulo. No caso da orquestra, o contrato de gestão foi firmado com a Fundação Osesp (Orquestra Sinfônica do Estado de São Paulo); na Pinacoteca, com a Associação Amigos da Pinacoteca.

Para debater esse tema e explicar como funciona a gestão de organizações culturais, a RAE convidou a Assessora Especial da Secretaria de Gestão Pública do Estado de São Paulo, Evelyn Levy, que participou do processo de implementação do modelo de OSs na área cultural em São Paulo, e o diretor executivo da Fundação Osesp, Marcelo Lopes.

Evelyn Levy foi subsecretária de Gestão e Recursos Humanos da Casa Civil em 2003. Entre 2001 a 2003 foi secretária de Gestão do Ministério do Planejamento, Orçamento e Gestão. Trabalhou também na Secretaria de Estado da Cultura, em São Paulo, durante o governo Alckmin. É doutora em Administração pela Fundação Getulio Vargas de São Paulo e professora de Gestão de Políticas Públicas da Escola de Artes, Ciências e Humanidades da USP (EACH/USP).

Marcelo Lopes integra desde 1984 o grupo de músicos da Orquestra Sinfônica do Estado de São Paulo, em que é trompetista. Formado em Administração Pública pela Fundação Getulio Vargas de São Paulo, Lopes também é economista e advogado e foi nomeado diretor executivo da Fundação Osesp em 2005. Na entrevista concedida à RAE, Lopes fala sobre as dificuldades que as organi- zações culturais enfrentam e sobre a adaptação do modelo de Organizações Sociais à área cultural, o que lhe parece muito vantajoso.

\section{EVELYN LEVY}

Em sua visão, quais as principais vantagens do modelo de Organizações Sociais, implantando na área cultural em 2004, em São Paulo?

Talvez devêssemos começar por explicar com qual sentido estamos empregando o termo "Organizações Sociais". Estamos falando de organizações do Terceiro Setor (públicas não estatais), que o governo contrata para gerir uma atividade apoiada e financiada pelo Estado. Necessariamente, são atividades em que a presença do Estado é estratégica, mas não exclusiva. Esse certamente é o caso da Cultura, campo em que convivem organizações privadas e públicas. E por que o Estado faz isso? Há inúmeras vantagens em delegar atividades a essas organizações não governamentais: o arcabouço jurídico no qual elas se inscrevem é muito mais flexível do que o das organizações estatais, afetando muitos aspectos organizacionais, como a Gestão dos Recursos Humanos. Por exemplo, no setor público, todas as admissões se fazem por concurso (exceto para os cargos comissionados, que, em geral, não chegam a 5\%), que é uma forma meritocrática com grandes virtudes, mas inadequada para contratar bailarinas e músicos, pois as provas têm de ser "objetivas", portanto, escritas. A autonomia financeira é maior, facilitando a gestão do dia-a-dia. Assim, uma diretora de museu não precisa pedir anuência da secretaria para consertar o muro que cerca a edificação. Por outro lado, as "Organizações Sociais" podem também procurar parcerias que venham a complementar os recursos estatais, ampliando o escopo dessas organizações e tornando esses recursos explícitos em prestações de contas adequados. Essas e outras questões acabam tornando essa modalidade muito mais adequada à execução de atividades culturais, educacionais, de pesquisa científica e tecnológica e de saúde. É evidente que essa delegação pressupõe, por parte do Estado, um controle competente de resultados e custos, e isso ele faz por intermédio de "contratos de gestão". Em suma, a principal vantagem da contratação de "Organizações Sociais" pelo Estado é sua comparativa flexibilidade administrativa, em face das regras jurídicas da administração pública, o que as torna muito mais eficientes.

Quais eram os problemas relacionados à administração das organizações culturais do governo do Estado de São Paulo, antes da adoção do modelo de OS?

A história do papel do Estado no âmbito da Cultura, no Brasil, foi muito errática. As organizações criadas por volta dos anos 1930 tiveram por objetivo preservar a memória cultural, focando um sentido de identidade nacional. Nos anos 1960, o Estado começa a intervir para apoiar a produção cultural, e assim continua a fazer nos anos 1970 e 1980. De um lado, a crise fiscal, e de outro, as novas demandas sobre o Estado no setor da Cultura frente à globalização, por exemplo praticamente desorganizaram esses setores estatais. Enfraquecido pela falta de recursos e despreparado para dar respostas a esses novos desafios, o setor estatal da Cultura viveu momentos muito difíceis. As respostas acabaram vindo por meio de novas iniciativas, com a ajuda de contribuições de empresas e da sociedade civil, que constituíram as sociedades amigas de museus, por exemplo. Sucede que não havia formas legais para abrigar esse novo desenho de parcerias que, 
de fato, estava se implantando. Em São Paulo, depois de a secretaria ter ficado virtualmente impedida de funcionar por falta de recursos humanos, buscou-se uma solução, posteriormente avaliada como equivocada. Assim, a despeito do florescimento das atividades da Secretaria Estadual da Cultura no período 1995/02, não havia formas de controle e contratação apropriados. O Ministério Público solicitou, então, a correção desses processos, e isso explica que, a partir de 2003, o governo estadual se dedique a reorganizar o setor.

O modelo de OS conseguiu corrigir esses problemas?

Acho que o modelo OS conseguiu muito mais que isso. Não só constitui uma resposta para regularização jurídica e administrativa dessas parcerias, como começou a produzir uma cultura de resultados e de gestão profissional. A introdução do modelo OS obriga o Estado a enunciar sua política cultural, o que havia se perdido. Os contratos de gestão criam oportunidades para se refletir sobre objetivos e metas dos programas culturais, formas de medir se esses objetivos estão sendo atingidos e revisão de custos dessas atividades. Adicionalmente, com o modelo de OS cria-se uma gestão profissional das instituições de cultura, o que significa maior previsibilidade, maior transparência no uso dos recursos, do recrutamento, além de maior flexibilidade. Isso resulta em maior agilidade nas decisões do cotidiano. Outros ganhos envolvem a realização de planos a curto e médio prazo e a possibilidade de acrescentar recurso por meio de doações.

A senhora vislumbraria alguma desvantagem no modelo de OS aplicado às instituições culturais, ou então pontos delicados que mereçam consideração?
Esse modelo implica uma governança, mais democrática e republicana, pois as principais decisões são explícitas e aprovadas por um conjunto de stakeholders: o governo, eventualmente um corpo de especialistas atuando como conselho consultivo do governo, a organização que gerencia a atividade e/ou programa, a sociedade (à medida que os contratos de gestão se tornam publicamente conhecidos) e as demais instâncias públicas (Tribunal de Contas) encarregadas do controle externo. Desse modo, o modelo funciona bem quando cada uma das partes entende o papel que tem a desempenhar. Assim, por exemplo, não cabe às OS definir a política cultural, o que continua sendo prerrogativa do governo. De outra parte, não cabe ao governo interferir no gerenciamento da instituição.

Você sente que há receptividade ao modelo ou se observam resistências? Há receptividade por parte de outras administrações estaduais, especialmente das que enxergam nesse modelo a possibilidade de expandir e/ou regularizar a ação do Estado na Cultura. A resistência existe, algumas vezes, por parte de organizações estatais, que receiam uma diminuição do fluxo de recursos ou temem não corresponder a um espírito empreendedor e de competência gerencial que, sem dúvida, o modelo necessita. A prática tem demonstrado, no caso de São Paulo, que o fluxo de recursos provenientes da sociedade civil aumenta e que o espírito empreendedor se desenvolve.

Em sua opinião, há alternativas, que não o modelo de OS, para a administração de organizações culturais do Estado?

Existe a figura da Organização Sociedade Civil de Interesse Público (OSCIP), bastante assemelhada à OS.
Ambas são organizações públicas não estatais que podem ser contratadas para a implementação de uma ação governamental. O que é importante assinalar é que o Estado contemporâneo caminha para um desenho que lhe dá maior responsabilidade na definição de políticas, articulação e controle de parceiros, delegando a terceiros a realização das atividades. Trata-se de um modelo mais complexo, mas em geral, mais eficiente.

Você poderia citar um exemplo de organização cultural bem administrada hoje no Brasil?

A implantação do modelo de Organizações Sociais (são agora 13 OSs) em São Paulo é relativamente recente, e, portanto, uma avaliação é precoce. Ainda assim, percebe-se uma mudança na qualidade da gestão, antecipando projetos, submetendo-os a um julgamento mais amplo, prestando contas com maior rigor. Todas as OSs ampliaram suas respectivas programações e oportunidades para a diversificação de produtores culturais. Creio que caminhamos para a consolidação de um modelo de gestão do setor cultural em que a presença do Estado cresce, respondendo a agendas de integração de sociedades fragmentadas, de múltiplas identidades culturais. Mas, ao mesmo tempo, isso ocorre sem onerar exclusivamente o Estado, dentro de padrões mais dinâmicos e de forma articulada a muitos parceiros - seja a própria sociedade civil ou as empresas.

\section{MARCELO LOPES}

Qual seu balanço das organizações culturais no Brasil? Elas conseguiram seguir o caminho de suas congêneres em países desenvolvidos, sobretudo no que diz respeito à capacidade de se financiarem? 
Com certeza já foram dados passos positivos e definitivos nessa direção. Observa-se isso na construção de mecanismos que conferem maior agilidade aos processos e à criação de controles internos, de modo que temos hoje uma visão melhor das instituições, suas peculiaridades e necessidades. É necessário, contudo, um melhor entendimento por parte dos governos para que percebam que a flexibilização da administração de atividades que tradicionalmente eram desempenhadas por órgãos públicos não se traduz em perda de poder, mas em ganho de eficiência e melhor prestação desses serviços. Há ainda uma confusão no que tange aos limites da normatização e poder de controle. Entendo que deve haver um fino controle das metas, mas que os meios para alcançá-las devam ser definidos pelo ente privado, nos moldes e padrões do mercado. Quanto à capacidade de autofinanciamento, na OSESP já conseguimos um aumento significativo das receitas próprias. Na medida em que vamos ampliando nossa capacidade de captação, conseguindo melhores quadros de funcionários e entendimento do "produto", esse crescimento vai se tornando mais sustentável.

Uma organização cultural pode ser administrada do mesmo modo que se administra uma empresa? Quais as semelhanças e/ou diferenças?

Pode e deve ser administrada como uma empresa. Estima-se que hoje $7 \%$ da economia mundial já é movimentada pela área cultural. Países que desenvolveram suas instituições culturais e aplicaram mais em educação tiveram resultados melhores nas últimas décadas. Sabemos que a difusão cultural é imprescindível em um mundo em que a produção industrial tende a empregar cada vez menos e a gerar menor renda e valor agregado. A cultura e os bens imateriais assumem cada vez mais um papel preponderante e têm um poder de alavancagem muito grande sobre os demais setores de serviços, turismo, transporte, etc. Logo, estamos falando de geração de emprego e renda; portanto, negócios. E isso exige boa administração, técnica, estudo e desenho de processos, rigor orçamentário e boa dose de empreendedorismo. Enfim, temos que lançar mão de todos os expedientes utilizados em uma empresa privada de alta performance.

E quais os limites entre a arte e os negócios? Como eles devem ser trabalhados?

O perigo aqui é querer fazer da lógica da acumulação e do lucro a meta principal da instituição. Devemos pensar social ou coletivamente. O balanço da atividade se dará em termos de ganhos sociais. A OSESP emprega 300 pessoas diretamente, e estimo que mais 800 ou 900 pessoas de forma indireta, nos vários setores envolvidos (hotelaria, transporte aéreo, serviços técnicos e especializados, etc). Porém, o objetivo principal será sempre o desenvolvimento artístico, a recriação da arte dos grandes mestres clássicos e a descoberta de novas formas de manifestação, descobrindo o espírito do nosso tempo, das cores e valores locais, buscar um quadro que revele a nossa realidade, no tempo e espaço que vivemos. É claro que quando falamos em arte de vanguarda não podemos submeter valores artísticos à lógica de mercado, o que seria vilipendiar a arte - e esse é o limite. Há que se ter critérios muito claros sobre a criação artística para não se cair no fácil, no vendável, no monetariamente lucrativo e se esquecer a liberdade de criação e a expressão artística.

Quais os principais desafios gerenciais que a orquestra enfrenta hoje? A OSESP foi fundada há mais de 50 anos e, nesse período, jamais teve uma administração profissional, sem ingerências políticas, e sempre foi muito indefesa em relação às marolas das alternâncias de poder. Assim, não houve a criação de uma cultura organizacional bem sedimentada em boas práticas administrativas. A mão-de-obra especializada é ainda um problema grave no setor cultural. Precisamos de bons gerentes, pessoas que vejam o mercado cultural de forma ampla, que entendam do negócio, mas com formação específica, que entendam também de gestão. Aqui estamos criando os controles internos da instituição, finalizando a implantação de um sistema integrado de gestão, aprimorando a contabilidade de custos, com centros de custos bem definidos, buscando ferramentas para um processo orçamentário confiável e controle dos resultados dos projetos. Foram criados manuais de compras e contratações, manuais de recursos humanos, regulamentos internos, sempre buscando as melhores práticas do mercado. $\mathrm{O}$ próximo passo é iniciar um planejamento estratégico de forma que possamos ter muito claros os caminhos da instituição a longo prazo.

Falando especificamente sobre o modelo de Organizações Sociais implantado na área cultural em 2004, em São Paulo, e adotado pela OSESP em 2005, quais são suas principais vantagens?

As principais vantagens são a flexibilização da gestão vis-à-vis a lei de licitações, Lei no ${ }^{\circ}$ 8.666, uma vez que o ciclo de produção da orquestra exige que se façam contratos com muita antecedência. Por exemplo, no momento já estamos negociando artistas convidados e turnês para 2009. No âmbito do Estado isso seria impraticável, na medida em que não poderíamos onerar orçamentos futuros com despesas correntes, por exemplo. De 
acordo com as regras de contratação do Estado, os músicos deveriam prestar concurso público e se incorporar a um grupo de funcionários públicos ou estatutários. O que acontece geralmente é que isso impede a renovação de quadros. Hoje os músicos se submetem a audições para admissão, são contratados pelo regime da CLT, mas regidos por regulamentos próprios, perfeitamente adaptados às especificidades da profissão, sem as amarras do serviço público. O controle do Estado ocorre apenas em relação às metas, deixando a cargo da executante a melhor forma de realizá-las. Isso é de suprema importância porque diminui sensivelmente a ingerência de agentes burocráticos que geralmente pouco sabem da atividade em si. Por fim, vejo ainda como vantagem do modelo de OS a possibilidade de criação de um fundo de capital (endowment) para fazer frente a futuros percalços financeiros e até mesmo diminuir a dependência de recursos do Tesouro.

Como a OSESP era gerida antes da adoção do modelo de OSs e quais eram os problemas enfrentados?

A OSESP era gerida pela Secretaria de Estado da Cultura. Os músicos tinham contratos de trabalho na figura de "credenciamento" (o que era irregular) e já havia, inclusive, um Termo de Ajuste de Conduta com o Ministério Público prevendo a extinção dessa forma de contratação. As receitas geradas pela bilheteria e cessão de direitos de imagem ou licenciamento de marcas tinham de ser obrigatoriamente revertidas para o Tesouro estadual e não havia garantia de serem reaplicadas na atividade, o que hoje aconte- ce. Outro problema era a dificuldade de buscar parcerias junto à iniciativa privada, já que é muito mais difícil conseguir patrocinadores ou doadores para órgãos da administração direta. Além dos problemas relacionados na pergunta anterior, posso enumerar ainda o descontrole de custos, uma vez que a Secretaria da Cultura não tinha pleno conhecimento dos custos envolvidos na atividade. Essa foi a maior dificuldade: definir um valor para o Contrato de Gestão que fosse compatível com a quantidade de metas e atividades desenvolvidas pela OSESP. Graças à implantação do modelo de OS, conseguimos corrigir vários desses problemas e estamos em processo de aprimoramento das ferramentas administrativas de tal modo que, em um futuro próximo, teremos um cabedal técnico e administrativo que poderemos dividir com instituições congêneres.

O senhor veria alguma limitação no modelo de OS, tendo em vista as especificidades enfrentadas por uma instituição cultural?

O processo de implantação foi muito açodado. Acho que há muito a aprender nos dois lados. As OSs precisam aprimorar sua gestão contábil e financeira, buscar transparência sempre. Por exemplo, a Fundação OSESP hoje é auditada pela PriceWaterhouseCoopers e os relatórios estão disponíveis no site da entidade. Por outro lado, o Estado precisa entender melhor o modelo. Há sempre uma tentativa de voltar a processos burocratizantes e controles exacerbados das atividades-meio, bem como um movimento teimoso de voltar a engessar a administração, perdendo-se assim a maior vantagem do modelo. Há a necessidade de se criar um ambiente que privilegie antes a parceria entre público e privado e não uma relação antagônica. Esse processo já está mais adiantado e maduro nas OSs da Saúde no estado de São Paulo, mas acredito que o amadurecimento ocorrerá também nas OSs da Cultura.

$O$ senhor sente que há receptividade ao modelo ou se observam resistências?

Não vejo resistências e entendo que na medida em que as OSs se fortalecem a receptividade aumenta. É claro que, para justificar sua existência, as OSs devem provar que sua administração é mais eficiente, com mais realizações (em número e qualidade) por usar mecanismos privados e uma legislação mais maleável. Se isso não ocorrer, o modelo não se sustenta, mas na OSESP as melhoras ocorrem a olhos vistos.

Em sua opinião, há alternativas ao modelo de OS para a administração de organizações culturais do Estado?

Para organizações culturais que dependem de verba pública, as OSs criaram condições para resolver problemas estruturais graves e seculares. Não tenho visto entidades culturais governamentais que não tenham sofrido muito com as vagas políticas e ao sabor da vontade de governantes mais ou menos afeitos à área cultural. Nesse sentido, o modelo de OS é uma luz no fim do túnel e um refrigério para a classe cultural.

Artigo convidado. Aprovado em 15.03.2007. 